En la España Medieval

ISSN: 0214-3038

http://dx.doi.org/10.5209/ELEM.56090

\title{
Fiestas e regozijos e alegrías. Los festejos taurinos en Medellín (c. 1446-c. 1543)
}

Julián Clemente Ramos ${ }^{1}$

Resumen. Las fiestas de toros tienen gran importancia y arraigo social en Medellín. Estos festejos, con un número limitado de ejemplares en cada caso, se suceden a lo largo de todo el año. Medellín recibe entre 10 y 12 toros de sus rentas, número insuficiente. Por ello, se consolidó la costumbre de recabar reses en las dehesas de la jurisdicción, en las que predomina el ganado vacuno. La lidia se realiza con un claro predominio de la modalidad popular, teniendo un escaso desarrollo el toreo caballeresco. Sólo se sacrifican algunos ejemplares, frecuentemente los mejores.

Palabras clave: sociedad; fiesta; fiestas de toros; baja Edad Media; siglo XVI; Extremadura.

\section{[en] Festivals, Rejoicing and Merriment. Bullfighting Festivities in Medellin} (c.1446-c.1543)

\begin{abstract}
Bullfighting festivities were extremely important and deeply rooted in Medellin's social life. These festivities, involving a limited number of animals in each case, were held all through the year. Medellin received between 10 and 12 bulls from its income, an insufficient number. This led to the custom of rounding up bulls in the grazing land under the town's jurisdiction, in which cattle farming was the main activity. Bullfighting was done largely by members of the local community, with the more formalised kind remaining undeveloped. Only a few animals, often the best, were sacrificed.
\end{abstract}

Keywords: Society; Festival; Bullfighting Festivals; Low Middle Ages; $16^{\text {th }}$ Century; Extremadura.

Sumario: 1. Introducción. 2. Las fiestas de toros: usos y arraigo social. 3. El encierro: de la dehesa a la plaza. 4. La lidia. 5. Conclusiones. 6. Bibliografía citada.

Cómo citar: Clemente Ramos, J. (2017) Fiestas e regozijos e alegrías. Los festejos taurinos en Medellín (c. 1446-c. 1543), en En la España Medieval 40, 249-267. 


\section{Introducción}

La fiesta ha generado un creciente interés entre los medievalistas y los historiadores en general en los últimos veinticinco años ${ }^{2}$. Inciden varios factores, como el deseo de una aproximación más completa a la realidad histórica que integre temas poco estudiados ${ }^{3}$ o la influencia de la historiografía foránea, en particular la francesa, que desde la década de 1960 cuenta con una importante línea de historia de las mentalidades ${ }^{4}$. No debemos olvidar los estudios pioneros y aún hoy imprescindibles de Julio Caro Baroja, que abordó en su conjunto y en su doble dimensión histórica y antropológica el hecho festivo en nuestro país ${ }^{5}$.

En Castilla, las fiestas de toros tienen una especial importancia. Fuera del ámbito estrictamente religioso, con el que por otro lado mantienen múltiples vínculos, constituyen la manifestación festiva por excelencia. Se documentan desde el siglo XII, por lo que su relación con manifestaciones muy anteriores no ofrece certezas ${ }^{6}$. Los festejos taurinos van unidos a evidentes manifestaciones de complacencia y alegría. Gozan de una enorme difusión y arraigo social ${ }^{7}$. Para algunos autores, las disposiciones de Alfonso X abrieron un periodo de dominio y desarrollo del toreo caballeresco, que habría mantenido su dominio hasta el siglo XVII ${ }^{8}$. Historia lineal y sin duda parcial, muy condicionada en algunos casos por un interés específicamente tauromáquico. La mediatización política, social e ideológica de los festejos taurinos no eliminó su carácter predominantemente popular'. No debemos olvidar la dualidad de la fiesta taurina en la actualidad. A la corrida se oponen los festejos tradicionales, que gozan de un mayor arraigo y presentan una mayor resistencia a cualquier hipotética desaparición. Muchas for-

M. A. Ladero Quesada, Las fiestas en la cultura medieval, Madrid: Areté, 2004, especialmente pp. 209-221.

3 No sorprende que en la década de 1990, como síntoma del desarrollo de esta nueva temática, se introduzcan apartados sobre la fiesta y la vida cotidiana en monografías sobre sociedades locales: Goicolea Julián, Haro:una villa riojana, pp. 232-257; Martín Cea, El mundo rural castellano, pp. 360-378

$4 \quad$ El trabajo de Heers, Fêtes, jeux et joutes (Conférence Albert-Le-Grand 1971) muestra el nuevo interés de la historiografía gala en el hecho festivo. En esta misma década aparecen trabajos importantes sobre esta temática como el de Emmanuel Le Roy Ladurie sobre el carnaval de Romans o el de Mona Ozouf sobre la fiesta revolucionaria.

5 Caro Baroja, El carnaval; Idem: La estación de amor; Idem: El estío festivo. Estos trabajos fueron publicados originalmente entre 1965 y 1984.

6 García-Baquero, "El toreo", p. 106; Badorrey Martín, Otra historia, p. 67. Bennassar, Historia de la tauromaquia, p. 19, señala como "ignoramos los orígenes exactos de los juegos y tratos festivos con el toro, cuyo más extenso y completo desarrollo quedó reservado a España". Esto ha dado pie a teorías de corte antropológico o pseudoantropológico que a Flores Arroyuelo, Correr los toros, p. 32, le producen "cierta dosis, o mejor una amplia dosis, de desconfianza". En todo caso, es una temática que situamos al margen del presente trabajo y que aquí, por razones de espacio entre otras, no abordaremos.

$7 \quad$ Felipe II contestará a intentos prohibicionistas que "esta es una antigua y general costumbre destos nuestros reynos, y para la quitar será menester mirar más en ello, y ansí por agora no conviene se haga novedad" (Sánchez-Ocaña, "Las prohibiciones históricas", p. 3). Sobre unos festejos celebrados en Valladolid en 1681, se indica que constituyen "el plato más delicioso, y de más regalado gusto, que el paladar de la lozana juventud, y aun de toda la nación española, puede desear" (Amigo Vázquez, "Fiestas de toros”, p. 288).

8 García-Baquero, "El toreo", p. 109; Ybáñez Worboys, "Divertimento", p. 305; Guillaume-Alonso, La tauromaquia, pp. 163-5; Bennassar, Historia de la tauromaquia, p. 35; Asenjo González, "Fiestas y celebraciones", p. 47.

9 Una visión documental muy exhaustiva, aunque con evidentes déficits analíticos, en Badorrey Martín, Otra historia, especialmente pp. 49-56 y 189-197. Igualmente, Viforcos Marinas, El León barroco, pp. 112 y 151 ; Amigo Vázquez, ;A la plaza!, pp. 150-1; Porras Arboledas, "Fiestas y diversiones”, p. 549; Jiménez Rodríguez, "Teatro y toros en Salamanca", p. 181; Graullera Sanz, "Fiestas con toros en Valencia", p. 84; Mateo Gómez, "La lidia de toros", pp. 174-181; Torres Martinez, "El léxico taurino", p. 146; Bennasar, Valladolid en el siglo de Oro, pp. 442-4. 
mas populares documentadas desde la época medieval o comienzos de la moderna se han mantenido hasta la actualidad ${ }^{10}$.

En las páginas que siguen estudiaremos este festejo en la tierra de Medellín, territorio que presenta un perfil peculiar. La jurisdicción, que ostentan los Portocarrero desde mediados del siglo XV, está mayoritariamente ocupada por dehesas en las que predomina el ganado vacuno. Medellín cuenta con una importante nobleza media, recuerdo de un antiguo y corto pasado realengo, que prácticamente monopoliza junto al monasterio de Guadalupe la propiedad de estos espacios. Su protagonismo se verá reducido por el intento condal de eliminar cualquier competencia política o social y de controlar estrictamente el concejo de la villa. Los festejos taurinos transcurren dentro de un perfil marcadamente popular. Se organizan preferentemente por los concejos de la villa o las aldeas y están claramente controlados por la autoridad jurisdiccional, pero no parecen ajustarse al modelo aristocrático o caballeresco. Las formas populares, dentro de una información no siempre precisa, parecen claramente dominantes.

No disponemos en Medellín de fuentes municipales para el periodo estudiado. La información que manejamos sobre los festejos taurinos procede casi exclusivamente de fuentes procesales provenientes de los archivos de Simancas (Cámara de Castilla, Consejo Real, en menor medida del Registro General del Sello) y Chancillería de Granada. Estas fuentes, que no han sido sistemáticamente explotadas, se caracterizan por su riqueza y por proyectar luz sobre realidades poco o escasamente documentadas. En ausencia de otros tipos documentales y si son abundantes, permiten estudios detallados y precisos como hemos demostrado en numerosos trabajos a lo largo de más de una década. En ocasiones, se insertan diversos documentos como prueba. Esto nos ha permitido disponer de unas tempranas cuentas concejiles en las que hemos podido documentar la recepción durante un siglo de toros en algunas rentas municipales. Especial importancia tienen diversos pleitos de la Chancillería granadina incoados en 1532 por el monasterio de Guadalupe contra el conde, diversos oficiales (incluidos el doctor Suárez, alcalde mayor) y vecinos de la tierra de Medellín por la recogida de toros para su lidia. Estos pleitos iluminan, a veces con gran detalle, aspectos poco tratados en otras fuentes como la conducción del ganado. Las fuentes procesales, no debemos olvidarlo, retrotraen la información bastantes décadas. En general, los testigos son de edad elevada y su memoria suele ser precisa desde los diez años, edad en que daba comienzo la actividad laboral. Por ello, la información suministrada se remonta en ocasiones más de medio siglo. Podría temerse una posible imprecisión, sin embargo la sistemática coincidencia aleja cualquier duda. Es sorprendente la fidelidad de la memoria de muchos testigos. En aquellos casos en que disponemos de otras fuentes de información, la coincidencia suele ser elevada. A todo esto tenemos que añadir informaciones de carácter más disperso. De este modo, hemos podido esbozar un siglo de festejos taurinos en sus grandes líneas esperamos que de modo consistente.

10 García-Baquero, "El toreo”, p. 109; Guillaume-Alonso, La tauromaquia, pp. 213-223. 


\section{Las fiestas de toros: usos y arraigo social}

Los festejos taurinos tenían, como hemos indicado, un enorme arraigo social. Sin duda, constituían la fiesta popular de mayor entidad. Toda festividad religiosa o celebración importante requería de la lidia de toros para completarse. De este modo, lo religioso y lo profano se fundían estrechamente. Estas fiestas generaban un consenso social sin fisuras.

La lidia de toros constituía un hecho festivo y alegre no exento de riesgo ${ }^{11}$, elemento que está en la base de la fiesta por encima de cualquier otro componente simbólico o religioso ${ }^{12}$. Pedro Gallego señala como "las gentes alegran e regozijan con ellos". Del mismo modo, Juan Bernal indica que "la gente se alegra mucho de ver correr los dichos toros"13. Debía ser frecuente la asistencia de vecinos de poblaciones cercanas. El día de Santiago de 1502 se desplazaron por esta razón bastantes o muchos vecinos de Medellín a Miajadas ${ }^{14}$. Del mismo modo, cuando se corrían toros en Medellín venían vecinos de otros lugares ${ }^{15}$. Estos eventos taurinos ejercían de este modo su atracción dentro del ámbito comarcal.

La mayoría de los festejos taurinos en Medellín, aunque están mediatizados por el conde, tienen un carácter concejil. Medellín recibía de forma regular, con cargo a diversas rentas, un número variable de toros ${ }^{16}$. En las cuentas de propios de 1446-7 consta la recepción de nueve ejemplares. Una situación muy similar se documenta, con más detalle, un siglo más tarde. El destino de estos toros no podía ser otro que el de su lidia y posterior aprovechamiento de la carne.

Cuadro 1. Rentas de Medellín: toros recibidos.

\begin{tabular}{|l|c|c|c|c|c|c|}
\hline Renta & $\mathbf{1 4 4 6 / 7}$ & $\mathbf{1 5 3 8 / 9}$ & $\mathbf{1 5 3 9 / 4 0}$ & $\mathbf{1 5 4 0 / 1}$ & $\mathbf{1 5 4 1 / 2}$ & $\mathbf{1 5 4 2 / 3}$ \\
\hline Verde & 1 & 2 & 2 & 2 & 2 & 2 \\
\hline Almotacenazgo & 1 & 2 & 2 & 2 & 2 & 2 \\
\hline Barcas & 1 & 2 & - & - & - & - \\
\hline Treintena & 1 & 1 & 1 & 1 & 1 & 1 \\
\hline Deh. Canchal & 1 & 2 & 2 & 2 & 2 & 2 \\
\hline Deh. la Matilla & $1^{1}$ & 1 & 1 & 1 & - & \\
\hline deh. Carrascal & 1 & 2 & 2 & - & - & - \\
\hline Renta viñas & - & - & 2 & 2 & 2 & 2 \\
\hline
\end{tabular}

11 Bennassar, Historia de la tauromaquia, p. 35; Martínez Shaw, "Un testimonio holandés”, p. 196.

12 Flores Arroyuelo, Correr los toros, p. 31

13 Arch. Chanc. Granada (=AChG), caja 1330, pieza 7-1, fols. 44v y 49v. Igualmente, en Valladolid estas fiestas se realizan para que "el pueblo goce"-septiembre, 1589-o "la villa se divierta"-julio, 1593-(Bennassar, Historia de la tauromaquia, p. 35).

14 A. G. Simancas, Consejo Real (=AGS-CR), leg. 56, exp. 2, fols. 178r y 184r: "el dicho conde en el dicho tienpo avia corrido toros en la villa de Meajadas... e los fueron a ver muchos vecinos desta villa"; "vido ir muchos vecinos desta villa de Medellin a Meajadas que corria el dicho conde toros".

15 "todos los vezinos de la dicha villa e los que alli querian yr se regozijaban con las dichas fiestas" (AChG, caja 1353, nº 9-4, fol. 145v).

16 Una realidad muy similar se documenta en otras villas castellanas y extremeñas: Izquierdo García, "El pueblo y la élite", p. 312, n. 14; Amigo Vázquez, "Fiestas de toros", p. 287; Badorrey Martín, Otra historia, pp. 106-7. Los carniceros también cumplen un papel importante en el suministro de los toros: Rodrigo Estebán, "Juegos y festejos", p. 753; López Martínez, Ganaderías de lidia, p. 52; Álvarez Cantos, "La fiesta de toros en Marbella", p. 99. 


\begin{tabular}{|l|c|c|c|c|c|c|}
\hline Bellota & 1 & - & - & - & - & - \\
\hline sin precisar & 1 & - & - & - & - & - \\
\hline TOTAL & 9 & 12 & 12 & 10 & 9 & 9 \\
\hline
\end{tabular}

Fuentes: ACG, c. 792, nº 1-4; AGS-CR, leg. 140, nº 2.

El peso del ganado vacuno en las dehesas de Medellín permitió el abastecimiento de los toros, aunque de modo forzado, dentro de la jurisdicción. Con la evidente colaboración de la autoridad condal se desarrolló la costumbre de recabar en las dehesas los animales necesarios ${ }^{17}$. Melchor Rodríguez nos informa de que existía "costunbre ynmemorial usada e guardada para las fiestas prinçipales del año y en tienpos de regozijo de traer los toros que les pareçe para los correr y matar en la dicha villa y lugares de su tierra". Los toros se cogían de "las dehesas sytuadas en el distrito e territorio de la dicha villa". Esta costumbre estaba ya consolidada a mediados del siglo XV. Martín Gamero señala como antes de 1460, cuando se corrían toros en la villa "enbian a los traer e traen de las dehesas". De este modo actuaban el conde Rodrigo Portocarrero (1449-1463) y luego su hijo Juan Portocarrero ${ }^{18}$. Hacia 1500 un alcalde de la Mesta emitió una sentencia sobre "el matar de las vacas e toros" en contra de otra previa de un alcalde de Don Benito. Esta última se ajustaba a una sentencia real de la que desconocemos su contenido ${ }^{19}$.

El concejo de la villa se encargaba de indemnizar a los propietarios de los toros. La cantidad establecida en el segundo cuarto del XVI para cada res sacrificada era de entre dos mil quinientos y tres mil maravedís. La cantidad debió resultar en bastantes casos insuficiente no tanto por el alto valor de los sementales cuanto por el daño que se producía en su actividad reproductora. Estamos ante algo que los ganaderos locales debieron asumir como un peaje social ${ }^{20}$. No debieron faltar roces ${ }^{21}$. Existía la costumbre de que la carne se repartiera "por los pobres y ospitales y por las personas que hazen las talanqueras". No podemos precisar la antigüedad de esta costumbre. Entre 1525-1532 parece no haberse respetado ${ }^{22}$. Fiestas y beneficencia social se juntaban sin duda para consolidar el arraigo social de estas fiestas ${ }^{23}$.

17 Prácticas similares se documentan en Jerez de la Frontera, a principios del siglo XVII, o en Mérida y Alange, en la primera mitad del siglo XVI (López Martínez, Ganaderías de lidia, pp. 50-51; Porras Arboledas, "Fiestas y diversiones", p. 532, n. 51). En otros casos, se prohíbe esta práctica o tiene un caracter excepcional: Uría Ríu, "Juegos y corridas de toros", p. 684; Del Campo, Pamplona y toros, p. 85.

18 AChG, caja 1353, no 9-4, fols. 126r y 148r-149v.

19 A. G. Simancas, Cámara de Castilla (=AGS-CC), leg. 11, no 394-5, fol. 1r.

20 AChG, caja 1330, pieza 7, fols. 25v-26r. A principios del XVI, el precio de un toro se estimaba en Valladolid habitualmente en tres mil maravedís (Izquierdo García y Milán Sarmentero, Los toros en Valladolid, pp. 44-6). Sobre el elevado precio de los sementales, Clemente Ramos, "Notas sobre el ganado vacuno", en prensa, pp. 9-13.

21 Hernán Galán nos indica, para el primer tercio del siglo XVI, como "algunas vezes los vaqueros se quexavan porque les trayan los dichos toros" (AChG, caja 1353, no 9-4, fol. 183r).

22 AGS-CR, leg. 140, exp. 2, fol. 277r y 341; igualmente, fols. 63r, 297v y 342r.

23 Esta costumbre debió alcanzar bastante difusión: Guillaume-Alonso, "De los ritos taurinos", pp. 123-4 y 126; Maroto Garrido, "La reorganización de las fiestas ", p. 143; Izquierdo García, "El pueblo y la élite”, p. 318; Badorrey Martín, Otra historia, pp. 29, 153-4 y 225.; Torres Martínez, "El léxico taurino en las fuentes medievales", pp. 146 y 161. Debemos vincularla, al menos en parte, a la escasa calidad de la carne de las reses lidiadas, que no dejan de registrar las fuentes históricas. En las ordenanzas de Coca de 1583 se indica que "se hace más pesada y no se hace buena, sino bermeja y algo dañosa, desabrida"-: Rodríguez Martínez, Ordenanzas, pp. 80-1; una perspectiva veterinaria en Pozo Lora, "Problemas de calidad", pp. 167-182. 
El monasterio de Guadalupe no siempre se posicionó contra esta costumbre. El procurador Melchor Rodríguez, en uno de los pleitos incoados por este monasterio entre 1529 y 1532, señala como los monjes "an reçibido paga de muchos toros que conforme a la dicha costunbre se an corrido en la dicha villa y lugares de su tierra". Otros testigos ratifican esta información añadiendo datos precisos que avalan su veracidad. Juan Bernal vio varias veces a vaqueros de Guadalupe cobrar la indemnización por los toros sacrificados. Hernán Galán oyó a un vecino como un mayoral del monasterio ofreció ejemplares mejores que los que se lidiaban ${ }^{24}$. Es posible que, como afirman los testigos del monasterio, no se cogiesen habitualmente reses de esta institución. Así lo afirma Gonzalo Hernández, que, sin embargo, "los veia llevar de las otras dehesas". El mayoral de Guadalupe, a requerimiento del conde de Medellín, entregó hacia 1518-9 un toro para su lidia "de buena gana pero no contra su voluntad".

Los festejos taurinos ocupaban gran parte del calendario anual. Todo parece indicar que había un elevado número de festejos en los que se lidiaba en cada caso un número limitado de reses. Las fiestas de toros no tienen en Medellín un carácter específicamente estival ${ }^{25}$. Los festejos comenzaban con la navidad y continuaban con los carnavales. Tras el receso de la cuaresma, volvían en festividades señaladas como Pentecostés o Corpus Cristi. Se registra un ciclo estival entre San Juan y San Miguel, con fechas señaladas como Santiago o Santa María de Agosto. El otoño marcaba un claro receso. Seguramente se desarrollaban eventos menos formales. Hemos documentado la lidia de una vaca en Rena proveniente de la renta de las vacas ${ }^{26}$ en octubre y de un toro en la dehesa de Santa María de la Vega en noviembre.

Cuadro 2. Medellín: calendario taurino.

\begin{tabular}{|l|l|c|}
\hline Estación & \multicolumn{1}{|c|}{ Fecha } & Año/costumbre \\
\hline \multirow{4}{*}{ Invierno } & Navidad & $1530,1531,1532$ \\
\cline { 2 - 3 } & Enero & 1531,1532 \\
\cline { 2 - 3 } & Carnaval & 1532 \\
\hline \multirow{5}{*}{ Primavera } & Pentecostés & 1530 \\
\cline { 2 - 3 } & Santísima Trinidad & 1530 \\
\cline { 2 - 3 } & Corpus Cristi & costumbre \\
\cline { 2 - 3 } & Junio & 1529,1530 \\
\hline
\end{tabular}

24 ACHG, caja 1330 , pieza 7-1, fols. 27v, 52v y 53v.

25 La concentración estival no es infrecuente: Jiménez Rodríguez, “Teatro y toros en Salamanca”, pp. 179-182; Izquierdo García, "El pueblo y la élite”, p. 310-1; Del Rey, "Toros en Bilbao”, p. 240; Fernández-Daza Alvear, "La actividad ganadera en Trujillo", p. 97; Porras Arboledas, "Fiestas y diversiones", p. 532-3, n. 52; Bernal Estévez, Mérida capital, p. 284-5

26 Sobre esta renta, vinculada al derecho vecinal sobre la montanera, cf. cf. Clemente Ramos, "El espacio pecuario", pp. 525-528. 


\begin{tabular}{|l|l|c|}
\hline Verano & San Juan (24-junio) & costumbre \\
\cline { 2 - 3 } & Santiago (25 julio) & costumbre \\
& Santa $\mathrm{M}^{\mathrm{a}}$ de Agosto & $1502,1529, i 1531 ?$ (Julio), \\
& & costumbre \\
& Santa $\mathrm{M}^{\mathrm{a}}$ de Septiembre & costumbre \\
\hline \multirow{3}{*}{ Otoño } & San Miguel & 15329, 1530? (agosto), \\
\cline { 2 - 3 } & Octubre & 1531 (vaca) \\
\cline { 2 - 3 } & Noviembre (lidia en dehesa) & 1528 \\
\hline
\end{tabular}

A las celebraciones ordinarias se añadían las extraordinarias, menos frecuentes. En general, estas celebraciones tienen que ver con eventos religiosos o de la reale$\mathrm{za}^{27}$. En Medellín, también están relacionados con la familia condal. Álvaro de la Cadena nos informa que en Medellín se han realizado "muchas alegrias e regozijos por buenas nuevas de los reyes de gloriosa memoria pasados e del conde". El nacimiento de Rodrigo Portocarrero, primogénito del segundo conde de Medellín, fue ampliamente festejado. También se celebró la conquista de Túnez en $1535^{28}$. Los festejos taurinos estaban vetados en situaciones de guerra o de muertes significadas ${ }^{29}$.

La mayor parte de estos festejos de carácter concejil se debieron desarrollar en Medellín. En un segundo lugar aparecen, muy vinculadas a la actuación condal, Miajadas o Don Benito. Menos información tenemos sobre otras aldeas. Juan Bernal alude a la lidia de toros en Mengabril ${ }^{30}$. Barrios y grupos profesionales, no sabemos con qué frecuencia, también organizaban festejos en Medellín. Del mismo modo, "los mançebos" de Don Benito compraron un toro para correrlo en Santa María de Agosto en $1531^{31}$. La vaca lidiada en Rena, aunque todos los vecinos se implicaran en el festejo, se vincula a la renta de las vacas, adscrita a los propios de la villa.

\section{El encierro: de la dehesa a la plaza}

El encierro de los toros ocasionaba en ocasiones largos recorridos ${ }^{32}$. En Medellín, el trayecto es siempre muy corto al desarrollarse dentro de la propia jurisdicción. Nada conocemos, salvo el abono del correspondiente gasto de encerradura, sobre el traslado de los toros devengados por las rentas. Nuestra información se centra en aquellas reses recabadas en las dehesas sin el acuerdo de sus propietarios. Todo comienza con una orden condal o de sus oficiales. El 15 de agosto de 1531 se ordenó a los alcaldes

27 Toro Buiza, Sevilla, pp. 51-3; Ybáñez Worboys, "Divertimento", p 307; Martínez Carrillo, "Elitismo y participación popular", p. 101

28 AChG, caja 1353, no 9-4, 145v; AGS-CR, Leg. 140, exp. 2, fol. 257r.

29 Se recuerdan como hechos irregulares que se corriesen toros después de "apregonada la dicha guerra de Françia [1502]" o cuando "el prinçipe don Juan, que santa gloria aya, ya era fallesçido desta presente vida [1497]" (AGS-CR, leg. 56, exp. 2, fols. 199r y 211r). Los lutos regios propiciaban la suspensión de los festejos taurinos (Amigo Vázquez, ;A la plaza!, p. 58).

30 AChG, caja 1330, pieza 7-1, fol. 49v.

31 Clemente Ramos, "Fiestas de toros y lidia popular", p. 1173; AChG, caja 1369, no 9-1, fol. 30v.

32 Del Campo, Pamplona y toros, p. 83; López Martínez, "De las vías pecuarias", pp. 255-261; López Izquierdo, "Ganaderos “, p. 92; Lope Toledo, "Logroño en el siglo XVI”, p. 267 
de Don Benito que con la gente necesaria fueran "a la ribera de Guadiana o a los Aguijones o a otra parte en termino de la villa de Medellin" a traer tres o cuatro toros, "los mejores que pudieredes hallar", y los trajeran a esta aldea ${ }^{33}$. El 20 de enero de 1532, se ordena a Alonso Hidalgo, Alonso Rodríguez y Serván Pajuelo que vayan "a qualesquier dehesas de este condado" a por otros tres o cuatro toros para ser corridos en Medellín. Se exige la colaboración de pastores y vaqueros ${ }^{34}$. El caso de Bartolomé Sánchez Cortillo es muy llamativo. Este vecino de Miajadas se encontraba "acostado en su cama" cuando tocaron a su puerta y le cometieron a que fuera a traer "çiertos toros" por orden del conde. En circunstancias similares se recabó la ayuda de Gómez Hernández o Juan Mateos ${ }^{35}$.

La recogida de los toros se enfrenta en ocasiones a la oposición pasiva o activa de los vaqueros. Actuaciones de este tipo dificultaban extraordinariamente la labor ${ }^{36}$. En junio de 1532, "porque se ponian delante para que no llevasen los dichos toros" se puso a un vaquero "una lança a los pechos" 37 . El enfrentamiento producido en la dehesa de Casa de la Vega fue incluso más duro. El conocedor Juan Gil y otros dos vaqueros, con sus yeguas y lanzas, intentaron impedir que se llevasen los toros. Tras el requerimiento, llegaron a arremeter, lo que originó una contestación y una amenaza de lucha a muerte. En este punto, los vaqueros de Guadalupe desistieron de su actitud $^{38}$. En la dehesa de Ventoso, un vaquero optó por espantar el ganado. Esto fue suficiente para que el grupo que venía a por los toros desistiera ${ }^{39}$. Habitualmente, los vaqueros se limitan a una resistencia pasiva, indicando su incapacidad para tomar cualquier decisión.

La recogida y conducción del ganado se realiza habitualmente a caballo y con una lanza u otra arma. La participación de vaqueros o personas duchas en su manejo es imprescindible. Los "cabestros y vacas para poder ençerrar los dichos toros" son insustituibles ${ }^{40}$. Estos animales pueden sufrir daños de diversa naturaleza, aunque en general de forma involuntaria ${ }^{41}$.

Conocemos algunas situaciones de peligro narradas de forma precisa, si bien se producen en contextos de lidia en el campo más que propiamente en la labor de selección. En enero de 1531, un toro en la dehesa de los Aguijones se fue hacia el

AChG, caja $1369, \mathrm{n}^{\circ} 9-1$, fols. $34 \mathrm{v}-35 \mathrm{r}$.

AChG, caja 1330, pieza 7-2, fol. 45r.

AChG, $1315, n^{\circ} 1-1$, fols. $27 \mathrm{v}$ y $28 \mathrm{r}-\mathrm{v}$.

36 Del Campo, Pamplona y toros, p. 83, nos indica la importancia de la colaboración de los vaqueros. En 1610, el regidor encargado en Pamplona se gastó un ducado y dieciocho reales en "los vaqueros de Fustiñana, Buñuel, Cortes y Valtierra, en convidarlos, por que le informasen de los mejores toros que había en sus vaquerías para comprarlos".

37 AChG, caja $1353, n^{\circ} 9-4$, fol. 211v

38 "entonçes el uno dellos arremetio a este testigo e a sus conpañeros a cavallo e con una lança en las manos, e que le dixo dexad los toros que yo juro a Dios que aunque soy viejo que tengo de llevar los toros e aun matarme con vosotros" (AChG, caja 1147, pieza 4-1, fol. 78v; también, fols. 76r-v).

$39 \mathrm{AChG}, 1315, \mathrm{n}^{\circ} 1-1$, fols. $28 \mathrm{v}-29 \mathrm{r}$.

40 Lope Toledo, "Logroño en el siglo XVI", p. 267; Izquierdo García, "El pueblo y la élite", p. 320; López Martínez, Ganaderías de lidia, p. 120; Guillaume-Alonso, La tauromaquia, p. 95; Del Campo, Pamplona y toros, p. 83; Viforcos Marinas, El León barroco, p. 130; en general, 130-2; Torres Martínez, "El léxico taurino en la obra cervantina", pp. 86-7.

${ }^{41}$ AChG, caja 1330, pieza 7-1, fol. 44r. Pedro Gallego indica que "algunas vezes a visto que no reçiben daño las dichas vacas e cabestros y otras vezes pareçe que la reçiben". El procurador Diego Pizarro señala como en junio y julio de 1529 cogieron cuatro toros del monasterio de Guadalupe y "llevaron con ellos muchas vacas y las hacosaron e corrieron de tal manera que no se ovo cria dellas" (AChG, 1330/7, fol. 13r). Normalmente se indica sobre estas vacas utilizadas en los encierros "que no se ovo cria dellas" (AChGra, 1330/7-1, fol. 3r; en general, fols. $2 \mathrm{v}-3 \mathrm{r}$ ). 
bachiller Medellín, que no pudo hacer otra cosa que ponerle la lanza con el resultado de que "se descabeço la lanza e le quedo el hierro dentro", a resultas de lo cual murió varios días después ${ }^{42}$. En Febrero de 1532, estando un grupo con el conde de Medellín "escaramuçeando" los novillos en la dehesa de Novillero, un toro "avia buelto hazia ellos" y Luis de Hermosa le dio una lanzada, que pese a los cuidados recibidos terminó ocasionándole también la muerte ${ }^{43}$.

Los toros se llevan en Medellín a un corral al que se alude en repetidas ocasiones $^{44}$. En realidad no estamos ante un corral anexo a la plaza, que sólo era un espacio sin ninguna infraestructura. Un testigo nos informa, de modo más preciso, que en agosto de 1529 los toros se encerraron "en el palaçio del señor conde" Las prendas de ganado realizadas por el conde se llevaban a un corral de su palacio "donde ençierran los toros" ${ }^{4}$. El corral indicado, por tanto, era el situado dentro del palacio condal. No olvidemos el papel protagonista del conde en todo lo relacionado con los festejos taurinos. En Miajadas, que contaba con un coso construido por el conde, los toros se encerraron en la navidad de 1531 en "un corral del dicho lugar" ${ }^{47}$. Los toros sólo permanecían algunas horas en estos corrales. Los encierros se realizarían, a juzgar por la información disponible, en la madrugada del mismo día de los festejos.

Algunos casos concretos nos permiten ver con más precisión todo el proceso. La actuación mejor documentada es la realizada en la navidad de $1531^{48}$. Conocemos la composición del grupo, el ganado recabado y las diversas contingencias que se produjeron. El conde ordenó a Pascual Sánchez y Tome Hernández, alcaldes de Miajadas, que fuese a buscar toros "donde los hallasen" en todo su condado. El grupo que se formó contó con una docena de personas armadas de lanzas, espadas $\mathrm{u}$ otras armas (garrote, aguijada). Inicialmente, parece que se dirigieron a la dehesa de Valverde aunque finalmente se dividieron, yendo una parte a las dehesas del Palacio (Monasterio de Guadalupe) y la Habilla (Mejía) y otra a Ventoso (Mejía). Es probable que se centraran sólo en la primera y última dehesa. En la del Ventoso les fue imposible recoger ningún ganado por la decidida actuación de los vaqueros, que espantaron el ganado. Uno de ellos les indicó la posibilidad de llevarse un toro que les señalaron pero "nunca lo pudieran arrancar de donde estava". Probablemente, no pudieron contar con las correspondientes vacas o cabestros. En la dehesa del Palacio apartaron inicialmente seis toros, pero a ruego de los vaqueros devolvieron cuatro de ellos. En esta dehesa, cogieron dos toros y probablemente dos cabestros, sobre los cuales la memoria de los testigos es muy poco precisa. Estos animales se encerraron en un corral en Miajadas.

También estamos relativamente bien informados de las actuaciones realizadas en enero de 1532 en la misma dehesa de Palacio ${ }^{49}$. El doctor Suárez, alcalde mayor, emitió el correspondiente mandato, seguramente con la anuencia condal. Participa-

\footnotetext{
${ }^{42}$ AChG, caja 1369, $\mathrm{n}^{\circ}$ 9-2, fol. 73r.; igualmente, AChG, caja 1330, pieza 7-2, fol. 26v, en donde aparece como protagonista Luis de Hermosa.

43 AChG, caja 1353, no 9-4, fols. 212v-213r.

44 "corral de la plaça de la villa de Medellin" (AChG, caja 1330, pieza 7-1, 19r; también, 20r). Igualmente: AChG, caja 1330 , pieza $7-2$, fol. $44 \mathrm{v}$, y caja $1369, \mathrm{n}^{\circ} 9-2$, fol. $91 \mathrm{v}$.

45 AChG, caja 1330, pieza 7-1, fol. 19r.

46 AGS-CR, Leg. 230, exp. 2-1, fol. 34r.

47 AChG, 1315, nº 1-1, fol. 27v.

48 En general para lo que sigue: $\mathrm{AChG}, 1315, \mathrm{n}^{\circ} 1-1$, fols. $27 \mathrm{v}-39 \mathrm{v}$.

49 AChG, caja 1330 , pieza $7-2$, fols. 25 y 44 ; y caja $1369, n^{\circ} 9-2$, fols. $69 \mathrm{v}$ y 72 r.
} 
ron varias personas, entre ellas algunos vaqueros. Se dirigieron a la dehesa indicada con la intención de coger "tres o quatro toros". Allí encontraron a dos vaqueros y un mozo que, tras enseñarles el mandato, les indicaron que no podían hacer nada sin que se lo ordenase el mayoral y "que... hiziesen lo que quisyesen". Apartaron un número posiblemente elevado de reses (toros, novillos, cabestros, quizás vacas) tras separarlos de su "querençia". Una vez apartados "los començaron a traer corriendo". Un vaquero del hato rogó al bachiller Medellín que apartasen los novillos porque recibirían mucho daño. Los dos se metieron entre las reses y los apartaron, devolviéndolos a la dehesa ("anda corre conmigo e corrieron e se metieron entre los novillos e los apartaron a un cabo"). Dicho bachiller había acudido a ruego del grupo actuante, aunque se intención era cazar en la vecina dehesa de los Aguijones, donde se quedó posteriormente. Finalmente, se llevaron ocho o nueve toros (alguno pequeño, quizás novillo), un novillo "castron" y un número impreciso de cabestros (el procurador del monasterio de Guadalupe incluye también vacas). Estas reses se llevaron al corral "de la plaça de la villa de Medellyn". Por la tarde, a la puesta del sol, cuando el bachiller Medellín regreso a la villa, aún se estaban lidiando.

\section{La lidia}

Los detalles sobre la lidia son escasos y reiterativos. Nuestras fuentes se centran preferentemente en los daños de las reses y su estimación. No hay un interés directo en los festejos taurinos y aún menos en la lidia.

En Medellín, al contrario de lo que solía ser habitual, no se utilizó la Plaza Mayor como coso taurino al menos desde principios del siglo $\mathrm{XVI}^{50}$. Los festejos se realizaban en el amplio espacio disponible que había junto al palacio condal, que debió construirse en el último cuarto del siglo XV. El nuevo coso medellinense simboliza la superior jurisdicción de los Portocarrero en detrimento de un concejo que muestra una dependencia creciente ${ }^{51}$. En 1502, el conde impidió la lidia de un toro alrededor de la iglesia de Santa Cecilia, ordenando que se hiciese "en la plaza" 52 . Es probable que este intento, además de otras connotaciones, tuviera que ver con el uso anterior de otros espacios. En 1506, se alude de modo inequívoco a la torre de Santiago, situada "en el coso junto con los palaçios del dicho señor conde" 53 . Conocemos relativamente bien este espacio que se llega a denominar como "la plaça del palaçio". Se situaba junto a la zona este de la muralla, cerca del castillo, la iglesia de Santiago y la torre del mismo nombre, sobre el actualmente exhumado teatro romano ${ }^{54}$. No había casas a su alrededor salvo el propio palacio condal y "otras dos casas que salen de la calle adonde entran en el dicho coso" 55 . Poco antes de 1540, el mercado franco

\footnotetext{
50 Amigo Vázquez, "Fiestas de toros”, p. 298; Izquierdo García, "El pueblo y la élite”, p. 314-5; Ybáñez Worboys, "Divertimento", p 308; Extremera, "Fiestas de toros", p. 111; Bonet Correa, Fiesta, poder y arquitectura, p. 20; Bernal Estévez, Mérida capital, pp. 285-6.

51 Sobre la escenificación del poder en los festejos taurinos: Amigo Vázquez, "Fiestas de toros", p. 295-308. El caso de Medellín presenta alguna similitud con León, donde el cabildo catedralicio y el concejo disputan sobre el lugar ideal para las corridas de toros: Viforcos Marinas, El León barroco, p. 97-102.

52 "mandaron que se corriese el dicho toro en la plaça, e que este testigo junto con otros no quisieron sino lidiallo alredor de la iglesia de Santa Çeçilia desta dicha villa" (AGS-CR, leg. 56, exp. 2, fol. 135r).

53 AGS-CC, leg. 11, nº 358, fol. 4r.

54 AGS-CR, leg. 230, exp. 2-1, fols. 113v y 129r.

55 AGS-CR, leg. 230, exp. 2-1, fol. 113v.
} 
también se trasladó allí desde la plaza de Medellín, buscando la proximidad al palacio condal y la mayor disponibilidad de espacio ${ }^{56}$.

El coso o plaza del palacio se preparaba con barreras. Entre aquéllos que recibían la carne de los toros estaban las personas encargadas de las talanqueras ${ }^{57}$. En Miajadas, el conde construyó un coso "de tapias" que le costó tres mil maravedís, lo que debemos vincular a su residencia temporal en esta aldea ${ }^{58}$. Ya estaba edificado en 1502.

Los toros lidiados eran habitualmente animales seleccionados y de elevado va$\operatorname{lor}^{59}$. Así sucedía de modo general en Medellín. Hacia 1517-1520, un mayoral de Guadalupe llegó a ofrecer por la insuficiente calidad de los toros "otros mejores" ${ }^{\circ}$. En agosto de 1531, se lidió "un toro castizo el mejor que hallaron", y en San Miguel de 1532, "tres toros, los mejores, e mas castizos" ${ }^{61}$. En general, se alude a toros grandes, castizos y buenos o muy buenos: "çenizo y muy bueno", "çenizo e muy bueno", "grandes y castizos", "toros castizos", grandes e muy hermosos" era normalmente un semental de más de cuatro años y con un peso relativamente importante. No deja de precisarse cuando el toro no se ajusta al perfil deseado. En agosto de 1532, se lidió un toro "de entre tres a quatro años çenizo" 63.

Además de los toros, también se lidian novillos. Sólo se documentan en dos casos. En uno de ellos se indica que eran cinco o seis. Más frecuentemente, hasta en cuatro ocasiones, se alude a las vacas. Normalmente se las menciona de modo genérico ("muchas vacas", "gran atajo de vacas") sin indicarse ninguna característica precisa. Más raramente aparecen los cabestros, cuya lidia documentamos en un caso aislado ${ }^{64}$.

Los toros no eran habitualmente, aunque si con cierta frecuencia, sacrificados en la plaza ${ }^{65}$. Esto sucedía con algo más de un tercio de los ejemplares. Los toros de las rentas quizás aumentasen esta proporción. En algunos casos, la muerte del toro puede considerarse accidental. De un toro se indica que murió "de las garrochas que le dieron" ${ }^{66}$. Un hijo del alcalde Alonso del Río, alcalde de Medellín desjarretó uno y debió pagarlo porque su actuación no fue previamente autorizada ${ }^{67}$. En los demás casos, el sacrificio de los toros forma parte de la propia fiesta y parece representar

AGS-CR, leg. 230, exp. 3, fol. 103r: "cabe la gente e bestias, aun carretas, e aun cabria mas de los que vienen"

AGS-CR, leg. 140, exp. 2, fol. 280r.

AGS-CR, leg. 56, exp. 2, fol. 178r.

59 Del Campo, Pamplona y toros, p. 83; Lope Toledo, "Logroño en el siglo XVI”, p. 266; López Izquierdo, "Ganaderos", p. 74; Clemente Ramos, "Notas sobre el ganado vacuno", pp. 9-13.

60 AChG, caja 1330, pieza 7-1, fol. 53v.

${ }_{61}$ AChG, caja 1330, pieza 7-1, fol. 2r, y AChG, caja 1147, pieza 4-1, fols. 76r-v.

62 AChG, caja 1330, pieza 7-1, fols. 1v, 3r y 22r; y caja 1147, pieza 4-1, fol. 42r. Se trata de algo habitual. En Málaga se lidian toros "buenos", "quitenos", "de quatro años arriba e no novillos", "buenos de abaxo" o "los toros mejores que se pudieren aver" (Ybáñez Worboys, "Los regocijos de toros", p. 229). Del mismo modo, Logroño encarga que se traigan toros "muy buenos", "los mayores que pudieran traer", "los mexores que hallaren” (Lope Toledo, "Logroño en el siglo XVI”, p. 266, a. 1577-1583).

63 AChG, caja 1330, pieza 7-1, fol. 19r.

64 "sacaron dos toros e uno bermejo y el otro ruvio... y dos cabestros con ellos del mismo hierro... y los metieron y acorralaron y agarrochearon de tal manera que los dichos toros salieron del coso donde los corrieron malparados e heridos" (AChG, 1315, no 1-1, fols. 39r-39v; se alude seguramente a la misma función en caja 1147, pieza 4-1, fol. 42r).

65 Del Campo, Pamplona y toros, p. 79 y 87-9; Uría Ríu, “Juegos y corridas de toros”, p. 685; Rodrigo Estebán, "Juegos y festejos", p. 751-2; Badorrey Martín, Otra historia, pp. 65-67.

66 AChG, caja 1330, pieza 7-1, 3r 1330, pieza 7-1, fol. 3r.

$67 \mathrm{AChG}$, caja 1369, n⿳0 9-1, fol. 31v: "dizen que lo dexarreto un hijo de Alonso del Rio, alcalde deste dicho lugar, y que el señor conde mando que pues lo dexarreto que lo pagase". 
su punto álgido. Es posible que se eligiera para ello a los mejores. Así sucede en dos casos, como veremos con más detalle.

Ya hemos indicado como, en Medellín, el calendario taurino se desarrolla a lo largo de gran parte del año. Esta relativa inflación de festejos quizás explique el limitado número de ejemplares, generalmente dos, lidiado en cada ocasión ${ }^{68}$. Así sucede en fechas significadas como junio (¿Corpus?), la festividad de Santiago o agosto (¿Santa María de Agosto?). En casos aislados, se lidia un número mayor de reses. Esta circunstancia sólo la documentamos en enero, que no se encuentra entre las fechas habituales de los festejos, y Santa María de Agosto. En enero de 1532 se lidiaron nueve reses, quizás más, en dos días. Un testigo señala que en el mismo mes del año anterior se trajeron de la dehesa de Palacio "syete o ocho toros y çiertos novillos". Los datos que ofrece nos hacen pensar que quizás se tratase del mismo festejo $^{69}$. En Santa María de Agosto de 1529, parece que se lidiaron cuatro ejemplares, aunque algún testigo sólo alude a $\operatorname{dos}^{70}$. En 1531, también se lidiaron en esta festividad en Don Benito cinco o seis toros de diversos propietarios ${ }^{71}$.

Los festejos taurinos habitualmente se desarrollaban bajo un estricto control de la autoridad jurisdiccional. La presencia del conde era habitual. Los diversos testigos aluden con cierta frecuencia a su participación directa o, en su defecto, a la de algún miembro de su familia. Es evidente que las fiestas taurinas constituían un escenario ideal para la manifestación y la materialización del poder. En la navidad de 1531, el conde, su hermano Alonso y algunos criados "les echavan garlochas e rehiletes" a dos toros en Miajadas ${ }^{72}$. Este control no siempre ha generado una lidia ajustada a los patrones del denominado toreo caballeresco. En general, los testigos de que disponemos dan alguna información de carácter genérico sobre la lidia. Esta se define por lo que parece una importante participación popular ${ }^{73}$.

La lidia probablemente no se ajustase a unas pautas precisas ${ }^{74}$. Se puede afirmar a partir de la información disponible que los animales sufrían un enorme castigo y que la participación directa en la fiesta no parece que fuera selectiva. Un primer elemento a considerar es la importancia de las armas arponadas. Se utiliza el término "agarrochear", frecuentemente junto a correr, de modo reiterado. Todo nos hace pen-

68 En villas y ciudades importantes suele lidiarse un elevado número de reses: Del Campo, Pamplona y toros, p. 73; Izquierdo García y Milán Sarmentero, Los toros en Valladolid, pp. 29-30; Ybáñez Worboys, "Divertimento", p 229. En Oviedo o Mérida sólo se lidiaban una o dos: Uría Ríu, "Juegos y corridas de toros”, p. 693-4; Bernal Estévez, Mérida capital, pp. 284-5.

69 Serván Pajuelo señala que "vido matar el uno y los otros despues de corridos los soltaron y los quatro dellos se quedaron en el corral hasta otro dia que los echaron fuera e ellos se salieron" (AChG, caja 1330, pieza 7-1, fol. 20r).

70 García Díaz, vaquero del monasterio de Guadalupe, alude a dos toros, "el uno hosco y el otro bermejo", que fueron sacrificados y otros dos que llegaron en mal estado (AChG, caja 1330, pieza 7-1).

71 AChG, caja 1369, no 9-1, fol. 31; AChG, caja 1330, pieza 7-1, fol. 2 r.

72 AChG, $1315, n^{\circ} 1-1$, fols. 30v, 34r y 37v. No es infrecuente la participación activa de miembros de la alta nobleza en estos festejos: Bennasar, Historia de la tauromaquia, p. 27.

73 El carácter eminentemente popular de los festejos taurinos ha sido señalado por algunos autores a partir de casos locales muy documentados: Viforcos Marinas, El León barroco, p. 112; Izquierdo García y Milán Sarmentero, Los toros en Valladolid, p. 72. En Pamplona se ha documentado una escasa presencia del toreo caballeresco: Del Campo, Pamplona y toros, pp. 146-151.

74 Del Campo, Pamplona y toros, p. 145, sostiene aún para el siglo XVIII que "Precisar cómo se desarrolla una corrida de toros en cualquier fecha del siglo XVII constituye para el investigador una ansiada meta, sin embargo, a través de la documentación conservada, la mayoría de las suertes que se realizaban, así como el orden de su ejecución, quedan sumidas en la penumbra". 
sar que las garrochas, que cobraron protagonismo desde el siglo $\mathrm{XVI}^{75}$, se utilizaban profusamente. La iconografía presenta toros con varas no muy largas sujetas a la piel $^{76}$. Estas garrochas, según Covarrubias, contaban "con un hierro de lengüeta, que es como garra" 77 , lo que facilitaba su fijación. Sobre el particular, es llamativo que se aluda a un toro lidiado en julio de 1529 que volvió a la dehesa con "dos hierros de garlochas en las ancas". Otro toro también se presentó un año después "con muchos hierros de garlochas"78. A juzgar por ejemplos como este último, las garrochas serían abundantes $^{79}$. También se lanzaban al toro "rehiletes" o "veeheletes". Posiblemente se trate de los pequeños dardos que aparecen en la iconografía y que menciona asimismo algún viajero ${ }^{80}$

Los toros no sólo sufrían el uso de garrochas o rehiletes. Los vecinos utilizaban también cualquier tipo de armas u objetos ${ }^{81}$. Hernán Martín de Jerez, mayoral del monasterio de Guadalupe, nos da ciertos detalles muy interesantes sobre la lidia de dos toros en la navidad de 1530. Se sacó al coso inicialmente uno de los toros y "lo corrieron muy gran rato con piedras, terrones e que... quando se llevava a las barreras le davan de guinchones con espadas e con lanças". A suplicas del mayoral, se devolvió al corral y se sacó el otro toro. A éste, igualmente, "corrieronlo otro gran rato con piedras, e terrones, e dandole guinchones quando llevava alguna barrera como al otro". Nuevamente, a petición del mayoral lo devolvieran al corral y sacaron otra vez el primero. Éste no parecía tener muchas ganas de volver al coso, razón por la que "le dieron muchos guinchones con una lança". En el coso, el conde y su hermano, le echaron "garrochas con hierros". Cuando estaba anocheciendo se soltó a los toros. Quedaron especialmente "corridos e maltratados" 82 . La situación es muy similar a la registrada en el corral de las casas de la dehesa de la Vega en noviembre de 1528. El conde estaba rodeado por su hermano y sus criados. El toro lidiado recibió "muchos palos e picotazos" $"$. Se utilizaron también terrones, piedras y palos. Los participantes se protegían detrás de las barreras. Todo indica una fiesta sujeta a pocas reglas. En todo caso, la participación popular parece importante en una fiesta en la que los modelos cortesanos parecen tener una escasa presencia. El uso de la capa debía ser relevante ${ }^{84}$. De otro modo no se explica el uso del verbo capear.

Especial importancia tiene el término alancear. No nos parece que en nuestras fuentes esté estrictamente relacionado con la lanzada caballeresca ${ }^{85}$, suerte reglada

\footnotetext{
Ybáñez Worboys, "Los regocijos de toros", p. 229

76 El viajero Laurent Vital alude a "varas de 10 pies de largo, armadas por un extremo con un punta de hierro aguda como una lezna", es decir, no arponadas (LAFRONT, Los viajeros extranjeros, p. 43).

77 Covarrubias, Tesoro de la lengua castellana, p. 631, fol. 430r.

78 AChG, leg. 1330, pieza 7-1, fols. 16v y 57v.

79 Los concejos encargaban centenares de garrochas para cada festejo taurino: Viforcos Marinas, El León barroco, p. 153; Del Campo, Pamplona y toros, p. 157-9; Uría Ríu, “Juegos y corridas de toros”, p. 702.

80 "les echavan garlochas e rehiletes", "çiertas garrochas y un vehelete" (AChG, leg. 1315, n" 1-1, fols. 30v y 34r). Las representaciones iconográficas suministran la información más clara sobre estas armas: Montero Agüera, Origen y evolución de los trebejos, pp. 22-24 y 29-31, fig. 5. Antoine de Brunel (a. 1655), alude en una corrida de Madrid, "al lanzamiento de algunas flechas o pequeños dardos" (LAFRONT, Los viajeros extranjeros, p. 66).

${ }^{81}$ Se documenta el uso de armas variadas en el toreo popular: Badorrey Martín, Otra historia, pp. 63 y 65; Torres Martínez, "El léxico taurino", p. 168.

82 AChG, caja 1353, no 9-4, fols. 214r-215v.

83 AChG, caja 1353, no 9-4, fol. $218 \mathrm{v}$.

84 Su uso está documentado desde fechas tempranas: Montero Agüera, Origen y evolución de los trebejos, p. 11; Rodrigo Estebán, “Juegos y festejos”, p. 751-2; Toro Buiza, Sevilla, p. 73.

85 Del Campo, Pamplona y toros, p. 370-373 y 389-392; Mena Cabezas, "Caballeros, toros y toreros", pp. $169-172$.
} 
y singular con la que se daba muerte al toro. El relato que hace Francisco de Amarilla, procurador del monasterio de Guadalupe, sobre hechos acaecidos en enero de 1532, es muy ilustrativo sobre la inexistencia de una vinculación estrecha entre alanceamiento y muerte del animal. En la fecha indicada, "corrieron e agarrochearon e alançearon" nueve toros y seis novillos en Medellín, matando sólo uno. Los demás volvieron "tan agarrocheados e alançeados" que ese año no produjeron al monasterio ningún beneficio ${ }^{86}$.

El término alanceamiento parece aludir a heridas reiteradas y de diferente factura producidas por la lanza que podían llegar a ocasionar la muerte del animal, habitualmente parece que accidental, por su reiteración. De este modo, animales alanceados salen vivos del coso. No estamos, por tanto, ante una suerte singular. Don Alonso, hermano del conde, dio "la primera lançada" en el festejo desarrollado en enero de $1532^{87}$. Este mismo año, Hernán Hidalgo también dio en la dehesa de Palazuelo la "primera lançada" a una vaca en "la llana del anca". Después, Diego de Trujillo le dio "otra lançada". Tras caer la vaca al suelo a consecuencia de las heridas "la acabaron de matar" 88 . La forma en que fue sacrificada esta vaca esta muy lejos de cualquier suerte reglada. El toro lidiado en la dehesa de la Vega en noviembre de 1528 ofrece un ejemplo muy similar. Un testigo nos indica que en el transcurso de la lidia "lo hirieron" y después lo soltaron. Una vez suelto fueron tras él a caballo y uno de los perseguidores "le dio una lançada e se a lobado". El toro murió por las heridas recibidas. El animal debió recibir la última lanzada en la parte trasera y no parece que su finalidad fuera darle muerte ${ }^{89}$. En ocasiones, el alanceamiento si se vincula a la muerte del toro aunque no a una suerte reglada. Así sucede con la vaca lidiada en Rena en octubre de 1531, que la "alançearon", en este caso mataron, los oficiales de Medellín y otros muchos vecinos de esta aldea ${ }^{90}$.

En general, la información sobre las formas de matar al toro es escasa e imprecisa. Se indica a veces que "mataron" algún ejemplar después de lidiarlo, correrlo y agarrochearlo. De un toro desjarretado se señala que "lo corrieron e agarrochearon y mataron". El . Eso del desjarrete sólo lo documentamos en dos ocasiones más en los que no fue autorizado. En Santa María de Agosto de 1531, el hijo de Alonso del Río, alcalde de Don Benito, desjarretó un toro que debió pagar por orden del conde ${ }^{92}$. En 1502, Diego Martín Barbero hizo lo propio con otro en una corrida de carácter vecinal, por lo que fue primeramente encarcelado y después condenado a entregar otro animal $^{93}$. Sin duda, el desjarrete requería de la previa autorización de la autoridad condal o en su defecto concejil. Todo parece indicar su uso habitual en el sacrificio de los toros. En otros casos, la muerte del toro sería una consecuencia del gran castigo recibido y tendría, en un sentido relativo, un carácter accidental.

\footnotetext{
AChG, caja 1330, pieza 7-2, fols. 29r-v y 45r.

AChG, caja 1330, pieza 7-2, fol. 80r.

AChG, caja 1147, pieza 4-1, fols. $82 \mathrm{v}-83 \mathrm{v}$.

AChG, caja $1353, n^{\circ} 9-4$, fols. $193 \mathrm{v}-195$ y $218 \mathrm{v}-219 \mathrm{r}$.

AChG, caja 1353, no 9-3, fol. 121r.

AChG, caja 1147, pieza 4-1, fol. 76v; y AChG, caja 1369, n 9-2, 69v: "los agarrochearon y corrieron y liviaron e mataron el mejor dellos"; "los capearon e corrieron e mataron uno dellos".

2 AChG, caja 1369, nº 9-1, fol. 31v.

93 "mandaron prender a este Diego Martin Barvero hasta que pagase el toro e depues lo condeno el dicho Lorenço Godoy que traxese otro toro para lidiar" (AGS-CR, leg. 56, exp. 2, fol. 153r).
} 
En general, los toros sufrían un enorme castigo y quedaban muy "maltratados". En algunas ocasiones se indica sobre alguno de ellos que volvió "flaco" "Conocemos bien el estado final de los ocho toros/novillos no sacrificados en enero de 1532. Los vaqueros llegaron a creer, dado el castigo recibido, "que los abian muerto". Ya en la dehesa, un vaquero consideraba probable que alguno de los animales muriera "porque tenia[n] muchos hierros". Cuatro ejemplares habían llegado en un estado muy malo: "tres dellos con hierros de garrochas hincados y el uno de los novillos con una herida en la pierna e una hinchazon tan grande como un copa de un sonbrero". Los otros cuatro, entre ellos un cabestro, también estaban "vien corridos e maltratados". Dos de los animales estaban cojos. Algunos tenían "dessollados los pescueços" ${ }^{95}$. El mejor indicador del estado en que quedaban los toros no sacrificados es que no podían cumplir sus funciones reproductoras. Se dice de uno, y es algo que con matices se repite de forma reiterada, que "no aprovecho ni tomo vacas porque vino maltratado y hostigado y andava apartado de las vacas que no salia al hato" $"$. No es extraño que el valor de estos toros sufriera una clara devaluación. Uno de los toros fue vendido, dado su estado lamentable, por mucho menos de lo que valía $^{97}$

En un contexto de dominio de un toreo popular, documentamos una referencia aislada a un torero llamado Alonso Hidalgo ${ }^{98}$. Es imposible precisar el papel jugado por este personaje. Es posible que este Alonso Hidalgo sea el mismo que aparece en enero de 1532 cazando con el bachiller Medellín y posteriormente ayudando en el encierro de los toros. Nada conocemos de su perfil profesional. Esta única referencia parece indicar un protagonismo escaso de estos especialistas, cuya actuación no parece que fuera habitual ${ }^{99}$.

La lidia de toros que hemos analizado tiene un gran parecido con los festejos populares actuales. Los toros sufrían un enorme castigo con garrochas, lanzas y otras armas de muy diversa naturaleza. El festejo y, en particular, la lidia se insertaban dentro de una rígida jerarquía política y social. El papel central del conde y su familia, que a veces llegaba a la intervención directa, es indiscutido. El alcalde mayor funcionaba habitualmente como su correa de transmisión. Los funcionarios concejiles, pese a la habitualmente exclusiva financiación municipal, asistían en una posición subordinada. Todo esto tenía su correspondiente plasmación urbanística. El coso se situaba junto al palacio condal, en el que se ubicaba el corral para los toros. Los vecinos, de modo generalizado, se sumaban a esa fiesta, específicamente popular aunque política y socialmente mediatizada, de modo activo y con un importante protagonismo.

\footnotetext{
AChG, caja $1353, n^{\circ} 9-4$, fols. 210v-211r; y caja 1330, pieza 7-1, fol. 55v.

AChG, caja 1330 , pieza $7-2$, fols. 50r, $80 \mathrm{v}$ y $81 \mathrm{v}-82 \mathrm{r}$.

AChG, 1330/7-1, fol. 56v.

AChG, 1353, n 9-4, fol. 215r.

"a Alonso Hidalgo como torero le dieron medio ducado por la faldura dellos" (AChG, caja 1369, n 9-2, fol. $69 \mathrm{v}$; igualmente, fol. 72).

99 Los matatoros aparecen sobre todo en el norte: Toro Buiza, Sevilla, pp. 43-4; García-Baquero, "El toreo", pp. 107-8; Del Campo, Pamplona y toros, p. 105; Badorrey Martín, Otra historia, p. 38. Guillaume-Alonso, La tauromaquia, pp. 227-9, señala dos posibles representaciones iconográficas de matatoros en el monasterio de Guadalupe y en la sillería del coro de la catedral de Plasencia.
} 


\section{Conclusiones}

Las fiestas de toros constituían un elemento festivo de la máxima importancia en Medellín. Suponían, además, un complemento en muchos casos imprescindible de la fiesta religiosa. Su arraigo popular explica el interés en su estricto control desde el ámbito jurisdiccional y concejil. Este control se visualiza en términos urbanísticos en la ubicación del coso junto al palacio condal, en detrimento de la plaza mayor. Pocos elementos como este muestran la subordinación del concejo, crecientemente tutelado, a la autoridad jurisdiccional.

A lo largo del año y especialmente entre navidad-carnavales y junio-septiembre se sucedían en Medellín numerosos festejos taurinos. El concejo recibía entre diez y doce toros de diversas rentas, número insuficiente. Desde fechas muy tempranas se consolidó la costumbre de recabar reses adicionales en las dehesas de la jurisdicción, donde predominaba el ganado vacuno, para su lidia sin la preceptiva autorización de sus propietarios. El concejo pagaba una cantidad fija por cada animal sacrificado. Sin duda, estamos ante un campo de fricción importante que afectaba sobre todo, por la composición de su cabaña, a los propietarios locales y al monasterio de Guadalupe. En cualquier caso, estos propietarios se veían obligados a pagar este peaje.

Sólo conocemos el encierro de las reses recabadas en las dehesas, pese a que el concejo abonaba la correspondiente "encerradura" de los toros de las rentas. Su recogida y conducción se desarrollaba entre la madrugada y el amanecer. Se lidiaban el mismo día. Los gastos por este concepto eran por ello mínimos.

Pese al estricto control que la autoridad condal mantenía sobre los festejos taurinos, la lidia parece un festejo fundamentalmente popular. Cualquier arma era adecuada, incluidas piedras y palos, aunque las garrochas tenían una presencia muy importante. La aproximación del toro a las talanqueras era aprovechada por todos los asistentes para pincharlo o lanzarle armas u objetos. La lanzada o el alanceamiento parece aludir habitualmente al uso de la lanza para hostigar y castigar al toro. Su finalidad directa no parece que fuera producir la muerte. Esto explica la aparente paradoja de que reses alanceadas salgan vivas del coso.

Una parte de los animales, en torno a dos tercios, vuelve a la dehesa después de sufrir un enorme castigo. Su estado les impide cumplir sus funciones reproductoras. En ocasiones, llegan a venderse a precio reducido. Estos animales debieron constituir la principal fuente de fricción con Medellín, que sólo indemnizaba por los toros sacrificados.

Los festejos taurinos, que se suceden a lo largo de casi todo el año, constituyen un acto festivo del que participaba con entusiasmo la totalidad de la población. Fuertemente controlados por la autoridad jurisdiccional, tienen un carácter marcadamente popular. Control político y entusiasmo popular definen unas fiestas imprescindibles que se desarrollan en la villa, las aldeas e incluso en espacios camperos.

\section{Bibliografía citada}

Álvarez Cantos, Fernando, "La fiesta de toros en Marbella durante el Antiguo Régimen", Cilniana. Revista de la Asociación Cilniana para la Defensa y Difusión del Patrimonio Cultural, 22-23 (2009-2010), pp. 95-116. 
Amigo Vázquez, Lourdes, "Fiestas de toros en el Valladolid del siglo XVII. Un teatro del honor para las élites del poder urbanas", Studia Historica. Historia Moderna, 26 (2004), pp. 283-319.

- iA la plaza! Regocijos taurinos en el Valladolid de los siglos XVII y XVIII, Sevilla: Maestranza de Caballería y Universidad de Sevilla, 2010.

Asenjo González, María: "Fiestas y celebraciones en las ciudades castellanas de la baja Edad Media", Edad Media. Revista de Historia, 14 (2013), pp. 35- 61.

Badorrey Martín, Beatriz (2015): Otra historia de la tauromaquia: toros, derechos y sociedad (1235-1848), tesis doctoral inédita: UNED, 2015 (URL: http://e-spacio. uned.es/fez/eserv/tesisuned:GeoHis-Bbadorrey/BADORREY_MARTIN_Beatriz_Tesis.pdf [consulta: 15-diciembre-2016]).

Bennassar, Bartolome, Historia de la tauromaquia. Una sociedad del espectáculo, Valencia: Editorial Pretextos, 2000.

- Valladolid en el Siglo de Oro: una ciudad de Castilla y su entorno agrario en el siglo XVI, Valladolid: Ayuntamiento, 1983.

Bernal Estévez, Ángel, Mérida capital y encomienda de la Orden de Santiago (14901530), Badajoz: Diputación, 2013.

Bonet Correa, Antonio, Fiesta, poder y arquitectura. Aproximaciones al Barroco español, Madrid: Akal, 1990.

Caro Baroja, Julio, El carnaval (análisis histórico-cultural), Madrid: Taurus, 1965.

- La estación de amor (fiestas populares de mayo a San Juan), Madrid: Taurus, 1979.

- El estío festivo. Las fiestas populares del verano, Madrid: Taurus, 1984.

Campos Cañizares, José, "El alanceamiento de toros. Una práctica festiva nobiliaria en la Alta Edad Moderna", en Miguel Salas Diaz, Susana Heikel y Gerardo Hernández-Roa (Eds.), Actas del XLV Congreso Internacional de la AEPE. El Camino de Santiago: Encrucijada de lenguas y culturas, Salamanca: Universidad de A Coruña, 2011, pp. 427-439.

Clemente Ramos, Julián, "Fiestas de toros y lidia popular en Medellín (c. 1500)", en Beatriz Arízaga Bolumburu et al. (eds.), Mundos medievales. Espacios, sociedades y poder. Homenaje al profesor José Ángel García de Cortázar, Santander: Universidad de Cantabria, 2012, vol. 2, pp. 1171-1176.

— "El espacio pecuario en Medellín (1450-1550)", Anuario de Estudios Medievales, 43/2 (2013), pp. 505-541,

- "Notas sobre el ganado vacuno en Extremadura a principios de la Edad Moderna: peso y sementales", en Antonio Malpica (ed.), Ganadería y Arqueología Medieval. XV Jornadas de Arqueología Medieval, Granada: Universidad de Granada, 2016, 15 págs. (en prensa).

Covarrubias, Sebastián de, Tesoro de la lengua castellana o española, Madrid: Turner, 1977 (edic. orig. 1611).

Del Campo, Luis, Pamplona y toros. Siglo XVII, Pamplona: Graficas Navasal, 1975. del Rey, Laura, "Toros en Bilbao en los siglos XVI y XVII. Del festejo popular al espectáculo", en Antonio García-Baquero González y Pedro Romero Solís (eds.), Fiestas de toros y sociedad. Actas del Congreso Internacional, Sevilla: Universidad de Sevilla, 2003, pp. 235-246.

Extremera Extremera, Miguel Angel, "Fiestas de toros en la Córdoba del Antiguo Régimen (siglos XVII-XIX)", Revista de Estudios Taurinos, 22 (2006), pp. 99131. 
Fernández-Daza Alvear, Carmen, "La actividad ganadera en Trujillo durante la Baja Edad Media”, en Jose Ángel Rodríguez y Salvador Rodríguez Becerra (coords.), Trashumancia y cultura pastoril en Extremadura, Mérida: Asamblea de Extremadura, 1993, pp. 89-106.

Flores Arroyuelo, Francisco J., Correr los toros en España. Del monte a la plaza, Madrid: Biblioteca Nueva, 1999.

García-Baquero González, Antonio, "El toreo en su historia”, en Antonio GarcíaBaquero González, Razón de la tauromaquia. Obra taurina completa, Sevilla: Fundación de Estudios Taurino, Universidad de Sevilla y Maestranza de Caballería, 2008, pp. 97-155.

Goicolea Julián, Francisco Javier: Haro: una villa riojana del linaje Velasco a fines del Medievo, Logroño: Instituto de Estudios Riojanos, 1999.

Guillaume-Alonso, Araceli, La tauromaquia y su génesis: ritos, juegos y espectáculos taurinos en España durante los siglos XVI y XVII, Bilbao: Ediciones Laga, 1994.

— "De los ritos taurinos y su evolución en los siglos XVI y XVII. Las Mondas de Talavera o Fiesta de los Toros", Cuaderna. Revista de Estudios Humanísticos de Talavera y su Antigua Tierra, 2 (1995), pp. 118-128.

Graullera Sanz, Vicente, "Fiestas con toros en Valencia en los siglo XIV-XVII", en Annie Molinié-Bertrand, Jean-Paul Duviols y Araceli Guillaume-Alonso (eds.), Des taureaux et des hommes: tauromachie et société dans le monde ibérique et ibéro-américain, París: Université de Paris-Sorbonne, 1999, pp. 77-92.

Heers, Jacques: Fêtes, jeux et joutes dans les sociétés d'Occident à la fin du moyen âge, Montréal: Institut d'Études Médiévales, 1971.

Izquierdo García, María Jesús, "El pueblo y la élite ante la fiesta de los toros. Valladolid y Palencia a fines de la Edad Media", en Manuel Rodríguez y Pedro Luis Huerta (coords), Vida cotidiana en la España medieval. Actas del VI Curso de Cultura Medieval, Madrid: Polifemo, 1998, pp. 303-328.

Izquierdo García, María Jesús y Milán Sarmentero, Marco Antonio, Los toros en Valladolid en el siglo XVI, Valladolid: Diputación Provincial, 1996.

Jiménez Rodríguez, Fernando,"Teatro y toros en Salamanca a principios del siglo XVII", Salamanca. Revista de Estudios, 15 (1985), pp. 159-182.

Lafront, Auguste, Los viajeros extranjeros y la fiesta de toros (siglos XVI a XVIII). Selección de textos inéditos, olvidados o desdeñados, Valladolid: Museo Nacional de Escultura, 1999.

Lope Toledo, José María, "Logroño en el siglo XVI. Toros y cañas”, Berceo, 68 (1963), pp. 257-278.

López Izquierdo, Francisco, "Ganaderos que lidiaron sus toros en Madrid en el siglo XVII", Revista de Archivos, Bibliotecas y Museos 88/1 (1975), pp. 69-92.

López Martínez, Antonio Luis, Ganaderías de lidia y ganaderos. Historia y economía de los toros de lidia en España, Sevilla: Universidad de Sevilla, 2002.

- "De las vías pecuarias a los ferrocarriles. El transporte de toros de lidia en España (siglos XVII-XX)", Revista de Estudios Taurinos, 22 (2006), pp. 249-272.

Mateo Gómez, Isabel: "La lidia de toros en el arte religioso español de los siglos XIII al XVI", en Manuel Núñez Rodríguez (coord.), El rostro y el discurso de la fiesta, Santiago de Compostela: Universidad de Santiago, 1994, pp. 173-184.

Martín Cea, Juan Carlos: El mundo rural castellano a fines de la Edad Media. El ejemplo de Paredes de Nava en el siglo XV, Valladolid: Junta de Castilla y León, 1991. 
Martínez Carrillo, María de los Llanos, "Elitismo y participación popular en las fiestas medievales", Miscelánea Medieval Murciana, 18 (1993-4), pp. 95-108.

Martínez Shaw, Carlos, "Un testimonio holandés sobre los toros del siglo XVII", Revista de Estudios Taurinos, 31 (2012):, pp. 193-198.

Maroto Garrido, Mariano, "La reorganización de las fiestas de Las Mondas: 1603”, Cuaderna. Revista de Estudios Humanísticos de Talavera y su Antigua Tierra, 2 (1995), pp. 129-14.

Masedo Torres, Fernando, Los toros en Badajoz (siglos XVI al XX). Historias, recuerdos, vivencias, Badajoz: Diputación Provincial, 2002.

Mena Cabezas, Ignacio, "Caballeros, toros y toreros en el siglo XVI. Un texto de don Luis Zapata", Revista de Estudios Taurinos, 8 (1998), p. 159-178.

Montero Agüera, Ildefonso, Origen y evolución de los trebejos utilizados en tauromaquia. Córdoba: Universidad de Córdoba, 1995.

Porras Arboledas, Pedro Andrés, "Fiestas y diversiones en Ocaña a comienzos del siglo XVI: Corpus Christi, toros, juego de pelota, mancebías, etc.", Cuadernos de Historia del Derecho, Extra 2 (2010), pp. 507-567.

Pozo Lora, Rodrigo: "Problemas de calidad en la carne del toro lidiado", Boletín de la Real Academia de Córdoba, 125 (1993), pp. 167-182.

Rodrigo Estevan, María Luz, "Juegos y festejos en la ciudad bajomedieval. Sobre el correr toros en la Daroca del siglo XV", Aragón en la Edad Media, 10-11 (1993), pp. 747-762.

Rodríguez Martínez, Felipe: Ordenanzas de la Villa y Tierra de Coca (1583), Coca: Comunidad de Villa y Tierra de Coca, 2003.

Sánchez-Ocaña Vara, Álvaro Luis, "Las prohibiciones históricas de la fiesta de los toros", Arbor, 189/763 (2013), doi: http://dx.doi.org/10.3989/arbor.2013.763n5011.

Toro Buiza, Luis, Sevilla en la historia del toreo, Sevilla: Universidad de Sevilla, 2002.

Torres Martínez, José Carlos de: “El léxico taurino en la obra cervantina", Revista de Dialectología y Tradiciones Populares, XXXIV (1978), pp. 79-107.

— "El léxico taurino en las fuentes medievales castellanas", Revista de Dialectología y Tradiciones Populares, 38 (1983), pp. 145-174.

Uría Ríu, Juan, “Juegos y corridas de toros en Oviedo de los siglos XV al XVIII”, en Juan Uría Ríu, Obra Completa. III. Estudios sobre Oviedo, Oviedo: Universidad de Oviedo, 2008, pp. 676-704.

Viforcos Marinas, María Isabel, El León barroco. Los regocijos taurinos, León: Universidad, 1992.

Ybáñez Worboys, Pilar, "Los regocijos de toros en los albores de la Modernidad", Baética. Estudios de Arte, Geografía e Historia, 19/2 (1997), pp. 223-232.

- "Divertimento en la sociedad renacentista: los festejos taurinos", en Antonio García-Baquero González y Pedro Romero Solís (eds.), Fiestas de toros y sociedad. Actas del Congreso Internacional, Sevilla: Universidad de Sevilla, 2003, pp. 303315. 